\title{
Control of phytoplankton production by physical forcing in a strongly tidal, well-mixed estuary
}

\author{
X. Desmit ${ }^{1}$, J. P. Vanderborght ${ }^{1}$, P. Regnier ${ }^{2}$, and R. Wollast ${ }^{1, \dagger}$ \\ ${ }^{1}$ Laboratory of Chemical Oceanography and Water Geochemistry and Department of Water Pollution Control, Université \\ Libre de Bruxelles, Boulevard du Triomphe (CP208), 1050 Brussels, Belgium \\ ${ }^{2}$ Biogeochemical System Dynamics, Department of Geochemistry, Utrecht University, PO Box 80.021, 3508 TA Utrecht, The \\ Netherlands \\ ${ }^{\dagger}$ Deceased on 28 July 2004
}

Received: 29 December 2004 - Published in Biogeosciences Discussions: 14 January 2005

Revised: 4 July 2005 - Accepted: 18 July 2005 - Published: 4 August 2005

\begin{abstract}
A zero-dimensional model for phytoplanktonic production in turbid, macro-tidal, well-mixed estuaries is proposed. It is based on the description of light-dependent algal growth, phytoplankton respiration and mortality. The model is forced by simple time-functions for solar irradiance, water depth and light penetration. The extinction coefficient is directly related to the dynamics of suspended particulate matter. Model results show that the description of phytoplankton growth must operate at a time resolution sufficiently high to describe the interference between solarly and tidally driven physical forcing functions. They also demonstrate that in shallow to moderately deep systems, simulations using averaged, instead of time-varying, forcing functions lead to significant errors in the estimation of phytoplankton productivity. The highest errors are observed when the temporal pattern of light penetration, linked to the tidal cycle of solids settling and resuspension, is neglected. The model has also been applied using realistic forcing functions typical of two locations in the Scheldt estuary. Model results are consistent with the typical phytoplankton decay observed along the longitudinal, seaward axis in the tidal river and oligohaline part of this estuary.
\end{abstract}

\section{Introduction}

Estuaries are often subject to high nutrient loads, which may lead to local eutrophication of the water masses. In turbid estuaries, however, phytoplankton respiration can exceed biomass production because of the low light penetration into the water column. This results in a negative depth-integrated

Correspondence to: X. Desmit

(xdesmit@ulb.ac.be) net primary production (NPP) (Grobbelaar, 1985; Reid et al., 1990; Cole et al., 1992; Heip et al., 1995). Nevertheless, high phytoplankton biomass concentrations are commonly observed in these environments (Kromkamp et al., 1995; Kromkamp and Peene, 1995; Heip et al., 1995 and references therein). Various authors have used the "critical mixing depth" approach introduced by Sverdrup (1953) to explain this apparent contradiction (Cole et al., 1992; Fichez et al., 1992; Irigoien and Castel, 1997). It is indeed well established that net phytoplankton production is determined by the ratio between critical and mixing depths, the former being defined as the depth at which vertically integrated photosynthesis equals vertically integrated respiration (Sverdrup, 1953; Grobbelaar, 1985; Cloern, 1987; Falkowski and Raven, 1997). In this production-loss balance, the first term (vertically integrated photosynthesis) not only depends on biological parameters: it is strongly linked to the light availability within the water column, which is itself controlled by physical forcing mechanisms. This control is particularly critical in turbid environments such as estuaries and coastal waters, which are often under the influence of significant particulate terrigeneous fluxes (Postma, 1980).

Phytoplankton production models currently incorporate an increasingly complex description of underlying biological mechanisms such as intracellular fluxes (Lancelot et al., 1994; Lancelot et al., 2000) and photoacclimation (Cullen and Lewis, 1988; Geider et al., 1996; Geider et al., 1998). In contrast, as pointed out for instance by Fichez et al. (1992), most studies on estuarine phytoplankton production have neglected the problems of fluctuating light regime as a major controlling factor. In particular, the coupling between primary production and sediment dynamics has been overlooked in the past, partly because the study of these processes

(C) 2005 Author(s). This work is licensed under a Creative Commons License. 
pertains to scientific disciplines that have largely evolved independently. Many authors have studied the correlation between phytoplankton production and turbidity, using the composite parameter $B Z E$ : biomass $B$, euphotic depth $Z$ and solar irradiance $E$ (Cole and Cloern, 1984; Harding et al., 1986; Cole and Cloern, 1987; Keller, 1988; Cole, 1989; Boyer et al., 1993; MacIntyre and Cullen, 1996). This empirical model may explain a large part of the variability of phytoplankton production in many estuaries, especially at the seasonal scale. However, the BZE model does not rely upon a physiological basis. In particular, it lacks any description of the phytoplankton response to light intensity (MacIntyre and Cullen, 1996). More critically, it does not link the value of the euphotic depth to the short-term suspended particulate matter (SPM) dynamics.

More recently, some authors have demonstrated how the short-term variation of various physical and biological processes influence the estuarine phytoplankton production. In particular, Lucas et al. (1999a, b) and Lucas and Cloern (2002) have shown that the interaction between water depth and bottom grazing may partially explain the occurrence of phytoplankton blooms in the South San Francisco Bay (SSFB). In their discussion over physical-biological phasing, they conclude that "other mechanisms of hourly scale variability $(. .$.$) - such as short-term variations in water column$ irradiance caused by tidally driven sediment resuspension and diel light cycle - could contribute additional hourly scale physical-biological phasing processes" (Lucas et al., 1999b).

Also in SSFB, May et al. (2003) have studied the short term variation of turbidity linked to wind-driven sediment resuspension. In this particular case, the tidal forcing is insufficient to resuspend sediments. This mechanism, and its coupling with the diel light cycle, have therefore not been considered in their work.

In this paper, the focus is on nutrient-rich, well-mixed tidal estuaries, where phytoplankton growth is not limited by nutrient availability, but where light is the crucial control factor. In such systems, it is expected that the underwater light field be not only determined by the incident solar irradiance, but also by the tidal influence on hydrodynamics and sediment transport (Wofsy, 1983). Estimating the combined effect of these forcing processes on the spatial and temporal evolution of phytoplankton production is clearly not a trivial question. The scope of this study is to assess the importance of the temporal, short-term variability of physical forcings and their interactions. More specifically, we investigate how short-term, tidally driven physical forcings interfere with the incident sunlight energy to sustain phytoplankton production in these environments. The impact of chlorophyll $a$ resuspension on the estimate of depth-integrated phytoplankton production is also discussed. Note that our focus is not on the role of the spatial (horizontal) variability of the phytoplankton production along the bathymetric gradient in an estuarine cross-section: this aspect has already been explored by a number of authors in the case of estuarine environments where extended shallow zones interact with deeper channels (Lucas et al., 1999a, b). The paper is structured as follows: first, a simple model of phytoplankton biomass for strongly tidal, well-mixed estuaries is presented. It is then applied to an idealized case using simple periodic forcing functions, in order to highlight the main features of the systems response. Finally, more complex forcing conditions are applied, taking the Scheldt estuary (Belgium, The Netherlands) as an example of a typical well-mixed, turbid system displaying a high dynamical suspended matter behavior (Fettweis et al., 1998).

\section{Model description}

The main purpose of this study is to investigate whether or not a positive algal growth can be sustained in a turbid, wellmixed estuary, where the mixing depth is always larger than the euphotic depth (i.e. where benthic photosynthesis does not occur). To answer this question, we hypothesize that the turbidity, and hence the light regime, is essentially controlled by local hydrodynamic conditions. In other words, the dynamics of suspended particulate matter (SPM) results mainly from local exchange fluxes with the bed through the processes of resuspension and deposition. This implies that the instantaneous current velocity is the key factor for turbidity. In addition, our focus is on the effect of local physical conditions on the sustainability of local algal growth; it is not on the effect of advective or diffusive transport on phytoplankton concentration along the longitudinal gradient. As a result, a simple box approach is adequate for our purpose. The use of more complex transport-reaction models of the estuarine continuum (e.g. Regnier and Steefel, 1999; Vanderborght et al., 2002) is therefore not required. Our modeling approach is very similar to the one of Lucas and Cloern (2002) who also neglected horizontal variability and transport processes in a zero-dimensional model of the phytoplankton dynamics in an idealized water column submitted to the semidiurnal tide.

\subsection{Governing equations for a well-mixed reservoir of os- cillating depth}

Consider a well-mixed reservoir of unit surface area, whose volume is changing with time due to the tidal variation of the depth $z_{\max }(t)$ (Fig. 1). The volume change is caused by a flow $Q(t)$ that is either positive or negative to account for level rise and level fall, respectively. To avoid dilution effects, the water added or withdrawn always has the same composition (including biomass and SPM concentration) as the water inside the reservoir. Solar light penetrating into the water is gradually attenuated within the water column: this well-mixed system is thus 0-D with respect to space for all constituents (including turbidity), yet it is a 1-D (vertical) system for photosynthetically active radiation (PAR). As a 
Table 1. Notation, value and units of the parameters used in the model.

\begin{tabular}{|c|c|c|c|}
\hline Parameters & Notation & Value & Units \\
\hline Specific photosynthetic efficiency & $\alpha^{B}$ & 0.05 & $\left(\mu \mathrm{gC} \cdot \mu \mathrm{gChl}{ }^{-1} \cdot \mathrm{h}^{-1}\right) \cdot\left(\mu \mathrm{mol} \text { quanta.m } \mathrm{m}^{-2} \cdot \mathrm{s}^{-1}\right)^{-1}$ \\
\hline Specific light-saturation rate of photosynthesis & $P_{\max }^{B}$ & 13 & $\mu \mathrm{gC} \cdot \mu \mathrm{gChl}{ }^{-1} \cdot \mathrm{h}^{-1}$ \\
\hline Rate constant for maintenance respiration & $\rho_{m}$ & 0.002 & $\mathrm{~h}^{-1}$ \\
\hline Growth respiration factor & $\rho_{g}$ & 0.3 & none \\
\hline Excretion factor & $\varepsilon$ & 0.03 & none \\
\hline Rate constant for mortality & $m$ & 0.002 & $\mathrm{~h}^{-1}$ \\
\hline Carbon: Chlorophyll $a$ ratio & $\theta$ & 50 & $\mathrm{gC} \cdot \mathrm{gChl}^{-1}$ \\
\hline Solar constant & $K_{\text {sol }}$ & 1367 & W.m ${ }^{-2}$ \\
\hline Sediment transport coefficient (location 1) & $X$ & 2000 & $\mathrm{mg} \cdot \mathrm{L}^{-1} \cdot \mathrm{m}^{3} \cdot \mathrm{s}^{-5}$ \\
\hline Sediment transport coefficient (location 2) & $X$ & 6000 & $\mathrm{mg} \cdot \mathrm{L}^{-1} \cdot \mathrm{m}^{3} \cdot \mathrm{s}^{-5}$ \\
\hline Wash load (location 1) & $Y$ & 40 & $\mathrm{mg} . \mathrm{L}^{-1}$ \\
\hline Wash load (location 2) & $Y$ & 25 & mg.L $\mathrm{L}^{-1}$ \\
\hline
\end{tabular}

result, the governing equation must be written in terms of the total biomass $B_{\text {tot }}$ within the reservoir:

$\frac{d B_{\mathrm{tot}}}{d t}=Q(t) B(t)+\frac{1}{\theta} \int_{0}^{z_{\max }(t)} r(z, t) d z$,

where $r(z, t)$ is the rate of phytoplankton biomass production at any time $t$ and depth $z$ within the reservoir. The conversion factor $\theta$ (chlorophyll $a$ to carbon ratio) is introduced in this equation for unit consistency. The algal biomass $B$ is related to $B_{\text {tot }}$ according to:

$B=\frac{B_{\text {tot }}}{z_{\max }}$,

while the rate of change of the water depth is given by:

$\frac{d z_{\max }}{d t}=Q(t)$.

\subsection{Rate of algal growth}

The rate $r$ of phytoplankton biomass production is given by:

$r=$ NPP-Excr-Mor,

where NPP is the net primary production of phytoplankton, Excr is the excretion rate (release of dissolved organic carbon) and Mor is the mortality rate of the algal cells. The net primary production is defined as:

$\mathrm{NPP}=\mathrm{GPP}-\mathrm{Resp}$,

where GPP is the gross primary production of phytoplankton and Resp is the algal respiration rate. All rates are usually expressed in $\mu \mathrm{gC} . \mathrm{L}^{-1} \cdot \mathrm{h}^{-1}$.

The relationship between GPP and PAR (in $\mu \mathrm{mol}$ quanta. $\left.\mathrm{m}^{-2} \cdot \mathrm{s}^{-1}\right)$ is modeled according to Platt's equation (Platt et al., 1980; MacIntyre et al., 2002):

$\mathrm{GPP}=B P_{\max }^{B}\left(1-e^{-\frac{\alpha^{B} \mathrm{PAR}}{P_{\max }^{B}}}\right)$

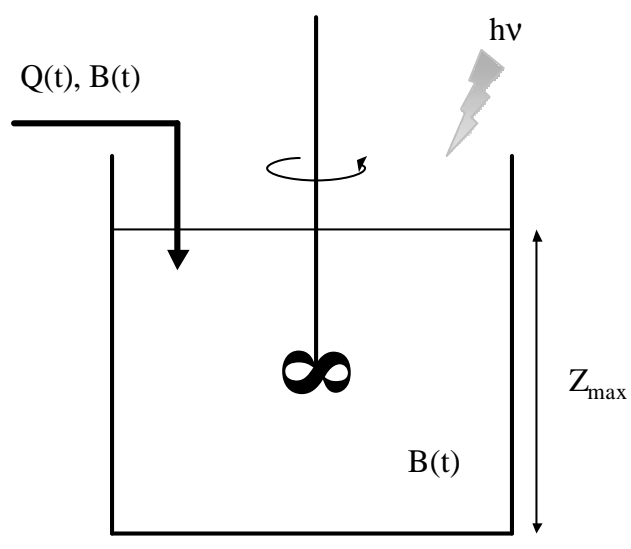

Fig. 1. Schematic representation of an oscillating-depth reservoir $(Q(t)=$ input/output flow; $B(t)=$ biomass concentration).

where the algal biomass $B$ is usually given in units of $\mu \mathrm{g}$ Chlorophyll $a \cdot \mathrm{L}^{-1} \cdot \alpha^{B}$ is the specific photosynthetic efficiency and $P_{\max }^{B}$ is the specific light-saturation rate of photosynthesis. Values and units for these parameters are presented in Table 1.

At least two additional processes are known to influence phytoplankton productivity: photoacclimation and photoinhibition. Experimental evidences of short-time photoacclimation, inducing changes in the photosynthetic parameters, have been previously obtained at the diel scale in turbid systems (see e.g. Harding et al., 1986; Prézelin, 1992). However, some authors argued that in a well-mixed and turbid water column, where the light history of algal cells is highly depending on turbulent mixing (Cullen and Lewis, 1988), phytoplankton is acclimated to a mean irradiance between the bottom and the surface (Demers et al., 1986; Mallin and Paerl, 1992). More recently, a number of authors have tried to link this variation of the photosynthetic parameters with 
the internal molecular machinery of the chloroplast (Geider et al., 1997; Kana et al., 1997; MacIntyre et al., 2002; Han, 2002). However, it remains difficult to transcript those detailed physiological description in the context of environmental modelling, especially when hydrodynamics is not resolved vertically (as it is the case in this paper). Also, it is difficult to identify from the experimental data what part of photoacclimation must be attributed to the incubation process, and what part may be attributed to the natural forcings in the environment. The consensus is thus not yet reached to know how far we must consider the short-time photoacclimation in the case of a turbid and tidal estuary. Though it is not the purpose of the present paper to answer this question, we have simulated different diel-variations of the photosynthetic parameters to see how such possible changes could affect our conclusions (see end of discussion).

When subjected to surface irradiances, phytoplankton cells may suffer photo-inhibitory effects, especially when acclimated to low-light intensities (Mallin and Paerl, 1992; MacIntyre and Cullen, 1996). However, photoinhibition is not an instantaneous process (Melis, 1999), and the timescale for full development of photoinhibition may vary between 0.5 and $1.5 \mathrm{~h}$ (Pahl-Wostl and Imboden, 1990). Thus, it is reasonable to assume that the response time of photoinhibition to changes in light regime is larger than the residence time of the cells near the water surface (Macedo et al., 1998). As a result, photoinhibition is ignored in Eq. (6). This hypothesis is obviously not valid in shallow estuaries, where light is available down to the bottom.

A proper parameterization of the phytoplankton respiration term is of crucial importance for our purpose. The simplest formulation for the respiration rate (Resp) is that it is simply a constant percentage of $P_{\max }^{B}$ (Steemann Nielsen and Hansen, 1959). Many authors have adopted this expression, using various coefficients of proportionality for different algal species (Gilstad et al., 1993; Langdon, 1993 and references therein). In light-limited environments where phytoplankton production is far from saturation, such an approach will lead to an overestimation of the respiration rate. Other formulations, which take into account intracellular mechanisms, have been proposed (Langdon, 1988; Lancelot et al., 1991, 2000; Lewitus and Kana, 1995) and are in agreement with laboratory measurements carried out on specific cultures of phytoplankton (Falkowski and Raven, 1997). In these models, algal respiration is divided into a maintenance term $\left(R_{m}\right)$ associated to basal metabolism and a growth or biosynthesis term $\left(R_{g}\right)$. This approach takes into account the light-dependency of respiration. For instance, some diatoms show a respiration rate in the light almost twice as large as in the dark (Weger et al., 1989). Following Langdon (1993), $R_{g}$ is expressed here as a fraction of GPP. $R_{m}$ is simply proportional to the algal biomass:

$\operatorname{Resp}=R_{m}+R_{g}$ with

$R_{m}=\rho_{m} B \theta$

and

$R_{g}=\rho_{g} \mathrm{GPP}$,

where $\rho_{m}$ is the rate constant for maintenance respiration and $\rho_{g}$ (comprised between 0 and 1 ) is the growth respiration factor. The values of $\rho_{m}$ and $\rho_{g}$ reported in Table 1 are adapted from Falkowski and Raven (1997).

To model the excretion rate of dissolved organic carbon (DOC), we follow the hypothesis that it is related to photosynthesis (Mague et al., 1980; Lancelot et al., 2000). Excr is thus expressed as:

$\operatorname{Excr}=\varepsilon \mathrm{GPP}$,

where $\varepsilon$ is the excretion factor. There is no typical value for $\varepsilon$, though common values are reported to be comprised between 0.03 and 0.2 (Malinsky-Rushansky and Legrand, 1996; Hansell and Carlson, 1998; Morán and Estrada, 2002). We hypothesize that in a nutrient-rich and light-limited system, algae are expected to allocate the major part of recent photosynthate to the biosynthesis of cellular constituents, instead of excreting it as DOC (Otero and Vincenzini, 2004). For this reason, a small $\varepsilon$ value $(0.03)$ has been used in the model.

The mortality of phytoplankton is described by a first order equation (Fasham, 1995):

Mor $=m B \theta$,

where $m$ is the mortality rate constant, which value is taken from Fasham et al. (1990). In our conceptual model, the grazing of phytoplankton is not explicitly described and is therefore included in the overall mortality term.

In well-mixed turbid waters, where light-scattering and light-absorbing particles are uniformly distributed, an approximately exponential decrease of the scalar irradiance is observed over depth (Di Toro, 1978). The time and depth variations of PAR may thus be described according to:

$\operatorname{PAR}(z, t)=E_{0}(t) e^{-k_{d}(t) z}$,

where $E_{0}(t)$ is the surface PAR and $k_{d}(t)$ is the vertical attenuation coefficient for scalar irradiance (Kirk, 1994). Since the system is vertically well mixed, $k_{d}$ can be taken as constant within the water column. Combining Eqs. (4) to (12) allows the computation of the rate of phytoplankton biomass production $r$ at any time $t$ and depth $\mathrm{z}$ :

$$
\begin{aligned}
& r(z, t)=B(z, t) \\
& {\left[P_{\max }^{B}\left(1-e^{-\frac{\alpha^{B} E_{0} e^{-k_{d} z}}{P_{\max }^{B}}}\right)\left(1-\rho_{g}-\varepsilon\right)-\left(k_{m}+m\right)\right] .}
\end{aligned}
$$

Substitution of $r(z, t)$ by expression (13) in Eq. (1) leads to an exponential-integral which has no exact solution in terms 


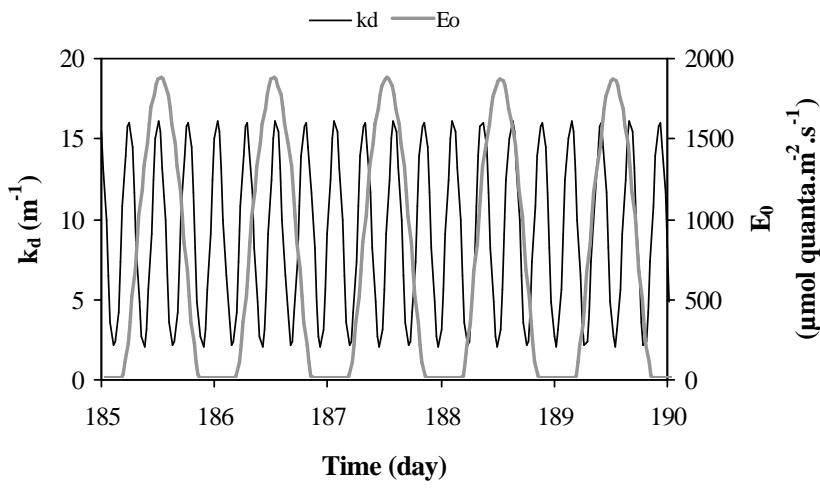

Fig. 2. Periodic forcing functions for the 1 st set of simulations: light attenuation coefficient for scalar irradiance $\left(k_{d}\right)$ and incident solar PAR $\left(E_{0}\right)$.

of elementary functions, and hence must be integrated numerically. As it appears from the equation above, the time dependence of $r(z, t)$ is ultimately controlled by the external forcing functions $E_{0}(t)$ and $k_{d}(t)$. The variable $z_{\max }(t)$ which appears in Eq. (1) introduces a supplementary forcing function with respect to time due to the tide. Internal model parameters are $\alpha^{B}$ and $P_{\max }^{B}$. Simulation results have been obtained numerically, using a spatial grid $(\Delta z)$ of $1 \mathrm{~cm}$ for the integration of $r(z, t)$ between 0 and $z_{\max }$ at a given time $t$, and a time step $(\Delta t)$ of $30 \mathrm{~min}$ for computing the evolution in time of $Q(t), B_{\mathrm{tot}}(t), B(t)$ and $\operatorname{GPP} z(t)$ using Eqs. (3), (1), (2) and (6), respectively.

\section{Forcing conditions}

As pointed out in the previous section, three forcing functions have to be specified to compute the temporal change of phytoplankton biomass: the incident PAR $E_{0}(t)$, the vertical light attenuation coefficient $k_{d}(t)$ and the total depth $z_{\max }(t)$, which is also equal to the mixing depth, and is generally larger than the euphotic depth in strong tidal, turbid estuaries. In a first set of simulations, these parameters are expressed in terms of simple periodic functions. The purpose of this simplified setting is to advance our conceptual understanding of the mechanistic interactions between the various physical forcing functions. The incident PAR $E_{0}$ has been estimated from a classical astronomical routine. It takes into account the total incident light energy $E$ at the top of the earth atmosphere, computed from the sun elevation $(\beta)$, the earth orbital radius $(R)$ and the solar constant $K_{\text {sol }}$ :

$E=K_{\text {sol }} \frac{\sin \beta}{R}$

where the time variations of the sun elevation and of the orbital radius are taken from Meeus (1998). In the case of a cloudless sky, a constant factor for light transmission through the atmosphere is considered (72\%). Reflection at the water

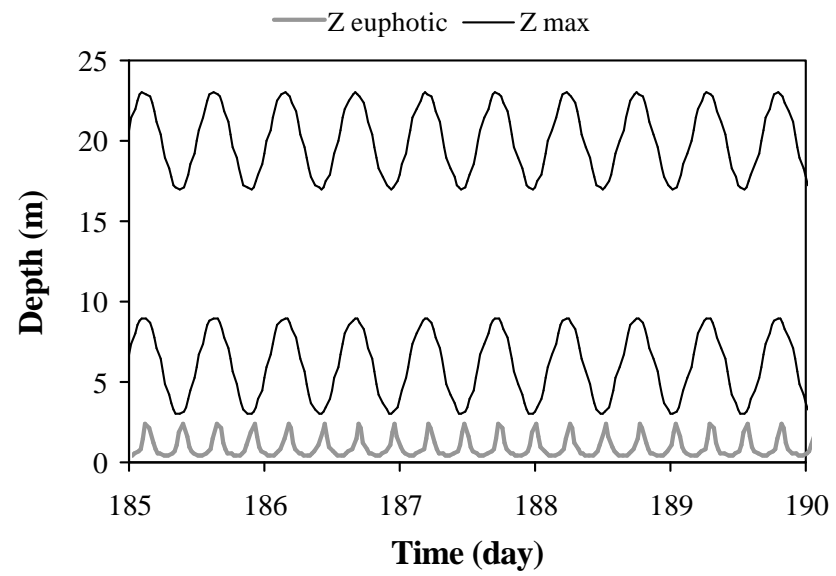

Fig. 3. Periodic forcing functions for the 1st set of simulations: water depth $z_{\max }$. The average depth (i.e. the depth at mid-tide) is comprised between $6 \mathrm{~m}$ and $20 \mathrm{~m}$, depending on the simulation. The tidal range is equal to $6 \mathrm{~m}$ in all cases. Euphotic depth, defined as the depth where $1 \%$ of the incident light is reached, is also represented. It is computed from the forcing function $\left(k_{d}\right)$ of Fig. 2, and is identical for all simulations. It is always smaller than the water depth $z_{\max }$.

surface is taken as a constant value (6\%). The PAR fraction of the total incident solar light is equal to $50 \%$. In the presence of a cloud cover (CC, expressed as a fraction between 0 and 1), a cloudiness factor CT is taken into account, according to:

$\mathrm{CT}=1-0.585 \mathrm{CC}$

(adapted from Vila et al., 1996). The grey line in Fig. 2 shows the temporal variation of $E_{0}$ that has been used for the simulations. It is typical for a cloudless, summer period (4 to 9 July) at latitude $52^{\circ} \mathrm{N}$.

Following the hypothesis that the current velocity is the key control factor for SPM and turbidity, the resulting tidal variation of the light absorption coefficient $k_{d}$ is approximated by a sine function of period $6 \mathrm{~h} 12 \mathrm{~min}$. This value corresponds to half the period of the M2 tidal harmonic (black line, Fig. 2) and allows reproducing the occurrence of two turbidity minima per tidal cycle, corresponding to low- and high-water slacks. Conversely, two turbidity maxima are also simulated, for maximum ebb and flood velocities respectively. The values selected for $k_{d}$ (between 2 and $16 \mathrm{~m}^{-1}$ ) are typical of turbid estuaries (Cloern, 1987). The resulting variation of the euphotic depth (defined as the depth where PAR is equal to $1 \%$ of the surface value) is represented in Fig. 3. Finally, the water depth $z_{\max }$ is also modeled using a sine function, but this time with a period $12 \mathrm{~h} 25 \mathrm{~min}$ and a tidal range equal to $6 \mathrm{~m}$. A set of scenarios is considered, ranging from a relatively shallow reservoir $\left(z_{\max }\right.$ varying between 3 and $9 \mathrm{~m}$, average value $=6 \mathrm{~m})$ to deeper systems $\left(z_{\max }\right.$ vary ing between 17 and $23 \mathrm{~m}$, average value $=20 \mathrm{~m}$ ) (Fig. 3). In 


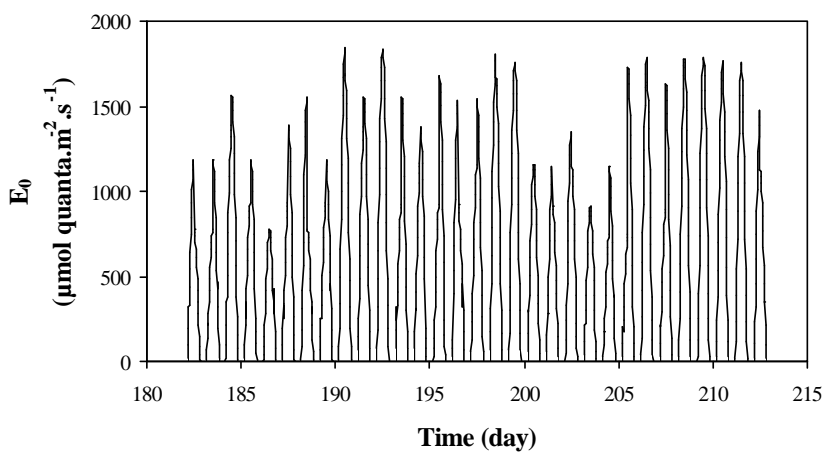

Fig. 4. Forcing function for the 2 nd set of simulations: incident solar PAR $E_{0}\left(\right.$ July $\left.1999,52^{\circ} \mathrm{N}\right)$.

all cases, the euphotic depth, which varies between 0.3 and $2.3 \mathrm{~m}$, represents only a small fraction of the total depth $z_{\max }$.

In a second set of simulations, we introduce the influence of natural variability on the forcing functions $E_{0}, k_{d}$ and $z_{\max }$, and we investigate the consequence of this variability on the primary production. Our purpose is to verify that the first-order features obtained in the previous set of simulations remain valid when more complex situations are described. By comparing the results of these simulations with experimental observations, we also aim at a validation of the model approach. The forcing functions are now parameterized from field data and from model results obtained for the Scheldt estuary (Belgium - The Netherlands), which can be considered as a typical example of a macro-tidal, turbid environment (Wollast, 1988). Two situations are considered, which differ in $k_{d}$ as well as in $z_{\max }$ (the incident PAR $E_{0}$ being identical in both cases). The first situation corresponds to a shallow site (location 1, representative of the fresh water zone situated in the tidal estuary, about $110 \mathrm{~km}$ of the estuarine mouth), while the second situation considers a deeper area of the estuary (location 2, typical of the brackish area around the harbour of Antwerp, $\mathrm{km} 80$ from the estuarine mouth). For $E_{0}(t)$, the same astronomical routine as above is used, but the resulting incident solar radiation is modified using a measured cloud coverage factor for temperate regions (July 1999, data supplied by IRM (1999), Fig. 4). The light attenuation coefficient $k_{d}(t)$ has been obtained from a large number of vertical light profiles and SPM measurements conducted throughout 2002. It is expressed as an explicit function of SPM:

$k_{d}=1.4+0.0592 \mathrm{SPM}$

with $k_{d}$ in $\mathrm{m}^{-1}$ and SPM in mg.L $\mathrm{L}^{-1}$ (Fig. 5). Note that self-shading by the phytoplankton is not accounted for in the model. In our test system (the Scheldt estuary), it generally plays a comparatively small role in the overall turbidity. Typical values of SPM concentration at the test sites are in the range $50-200 \mathrm{mg} . \mathrm{L}^{-1}$, whereas phytoplankton biomass is most of the time lower than $10 \mathrm{mg} . \mathrm{L}^{-1}$ (dry weight). Di-

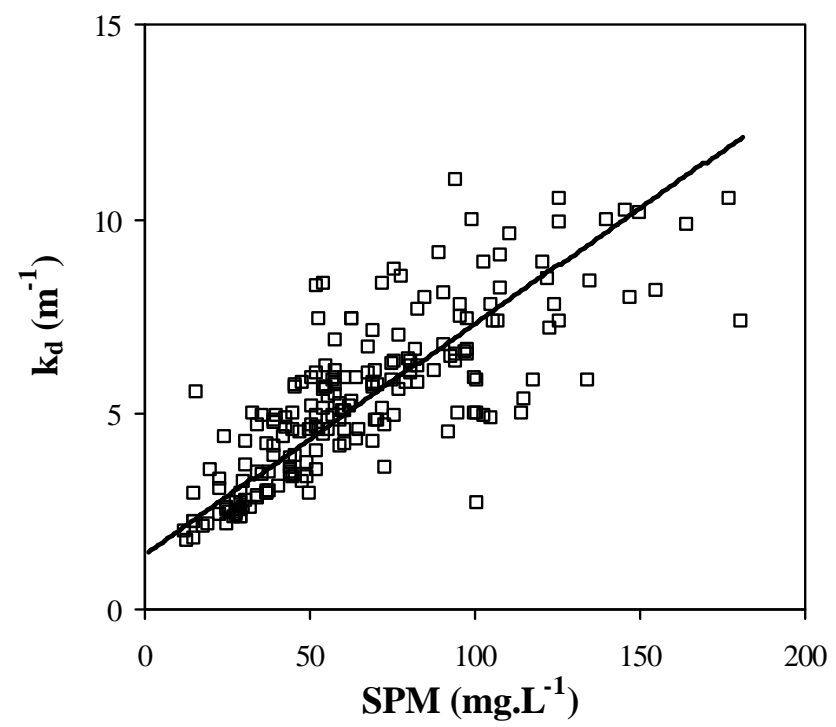

Fig. 5. Linear relationship between $k_{d}$ and SPM as measured in the Scheldt estuary $\left(k_{d}=1.4+0.0592 \times \mathrm{SPM} ; r^{2}=0.609\right)$.

rect determination of the scalar absorption coefficient $k_{d}$ has also been performed, following a method adapted from Kirk (1994). Given that the vertical light profile is decreasing exponentially, the value of $k_{d}$ can simply be obtained by measuring the irradiance $E_{d}$ at two different depths $z_{1}$ and $z_{2}$ :

$k_{d}=\frac{1}{\left(z_{2}-z_{1}\right)} \ln \frac{E_{d}\left(z_{1}\right)}{E_{d}\left(z_{2}\right)}$.

The in situ measurements have been made using two spherical quantum sensors (Aquamatic AQPL-UV912) separated by a constant, known vertical distance $(\sim 50 \mathrm{~cm})$. This technique eliminates the need for incident light compensation and allows the continuous logging of the $k_{d}$ value. An example of results for the Scheldt is given in Fig. 6. In addition, vertical profiles of scalar irradiance have repeatedly shown that the $k_{d}$ value can be considered as constant with depth in this well-mixed estuary, at least in the euphotic layer (Fig. 7).

In this second set of simulation, the SPM concentration is estimated using the concept of maximum transport capacity, which allows expressing the particulate matter content as a function of the local instantaneous current velocity and water depth (Verbanck, 2003):

$\mathrm{SPM}=X{\frac{|u|}{z_{\max }^{2}}}^{5}+Y$

where $|u|$ is the modulus of the cross-sectional averaged velocity and $X, Y$ are two constants. The two variables $u$ and $z_{\max }$ are obtained from a one-dimensional hydrodynamic (HD) model of the Scheldt estuary (Regnier et al., 1998), which not only resolves the tidal timescale, but also incorporates the longer term neap-spring oscillation and the variation of the freshwater discharge. For the shallow zone (Fig. 8a), 


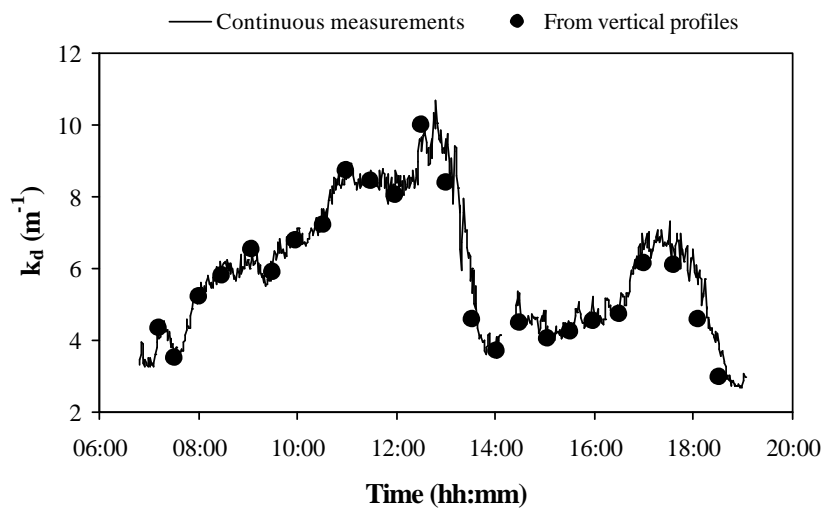

Fig. 6. Time variation of the light extinction coefficient for scalar irradiance during a complete tidal cycle (km 115, 22 August 2002).

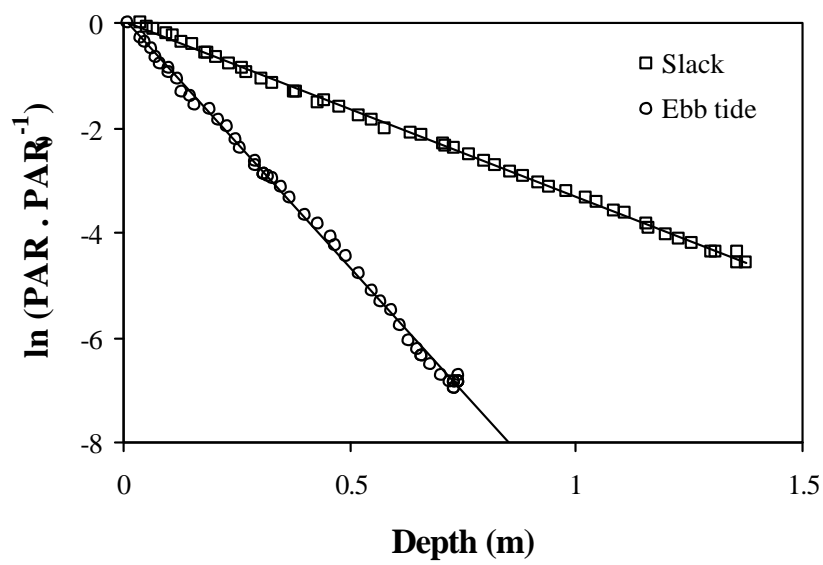

Fig. 7. Vertical profile of scalar irradiance measured in the tidal Scheldt estuary (km 115, 22 August 2002).

$z_{\max }$ varies during the tide between $4 \mathrm{~m}$ at low tide and $9 \mathrm{~m}$ at high tide (tidal range $=5 \mathrm{~m}$ ); in the deeper area (Fig. 8b), these values are respectively equal to $10 \mathrm{~m}$ and $16 \mathrm{~m}$ (tidal range $=6 \mathrm{~m})$.

In Eq. (18) above, the constant term $Y$ corresponds to the finer particulate material, which remains in suspension in the water column (wash load). The coefficient $Y$ is essentially dependent on the nature of the suspension, which can vary along the estuarine gradient. In order to reproduce the SPM concentration range commonly observed in the two areas, distinct values for the constants $(X, Y)$ have been used for the simulation: $X=2 \times 10^{3}$ and $Y=40$ for the shallow, freshwater tidal estuary; $X=6 \times 10^{3}$ and $Y=25$ for the deeper, brackish region. The resulting variations of $k_{d}$ for both situations are represented in Fig. 9. Despite its simplicity, this approach provides a realistic first-order description of the SPM and $k_{d}$ dynamics, as shown by the comparison between the turbidity measured at a monitoring station located in a zone of high SPM content ( $\mathrm{km} 80$ from the mouth) and the results of a simulation carried out for the same location (Figs. 10b (a)

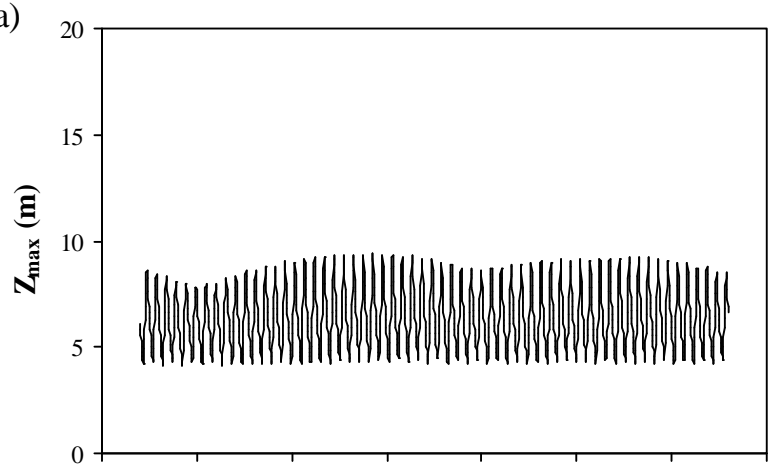

(b)

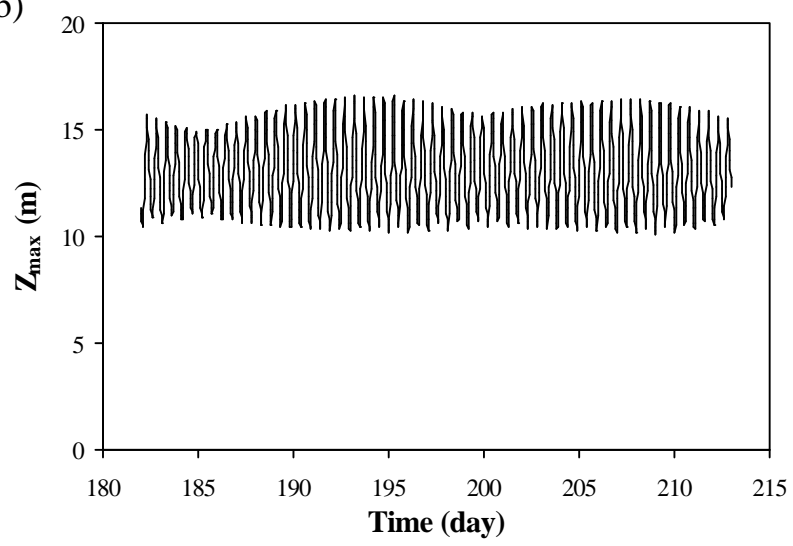

Fig. 8. Forcing function for the 2nd set of simulations: water depth $z_{\max }$. (a) shallow area, (b) deeper area.

and 10c). Two peaks per tidal cycle can be observed, corresponding to maximum ebb and flow velocities. The very fast settling of suspended solids at slack water is another salient feature of the observed and modelled SPM dynamics.

Because the tidal velocities computed by the HD model are essentially similar in the shallow and deeper areas, the SPM, and hence the $k_{d}$, differ mainly via the influence of $z_{\max }$, according to Eq. (18). Comparing Figs. 9a and 9b shows indeed that the resulting $\mathrm{k}_{d}$ is on average higher at the shallow site than at the deeper site. In both cases, the water depth and the light attenuation coefficient are strongly modulated by the spring-neap oscillations.

\section{Dynamics of phytoplankton growth}

\subsection{First set of simulations}

The results of the simulations obtained when using simple, periodic forcing functions for $E_{0}, k_{d}$ and $z_{\max }$ are synthesized in Figs. 11a to 11c. Figure 11a shows the time evolution of the PAR, immediately below the water surface $\left(E_{0}\right)$ and at a depth of $20 \mathrm{~cm}$. This latter depth has been selected for the illustration, because the amplitude of light intensity variation is still high, but the temporal variation is already very differ- 

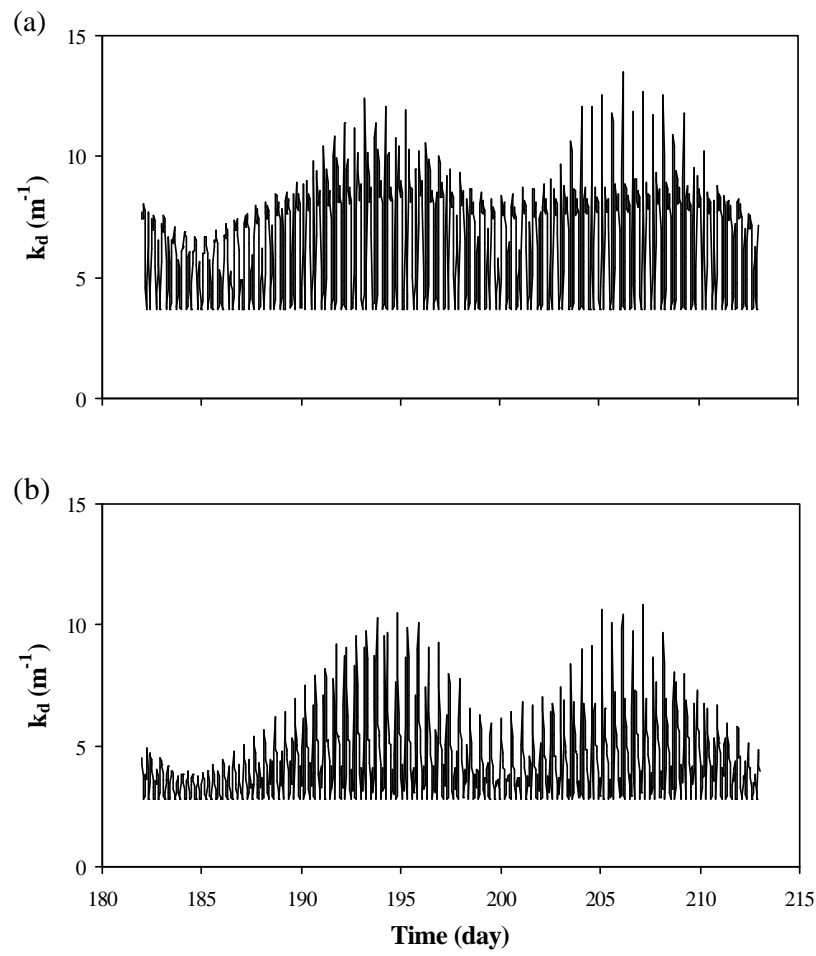

Fig. 9. Forcing function for the 2nd set of simulations: light attenuation coefficient $k_{d}$. (a) shallow area, (b) deeper area.

ent from the purely sinusoidal signal at the surface. A complex, multiple-peak pattern is obtained, which results from the modulation of $E_{0}(t)$ by $k_{d}(t)$. Because these two signals have different frequencies, the underwater PAR shows two or three daily peaks with a progressive phase shift in the daily maximum. This idealized simulation demonstrates that the maximum underwater PAR is most of the time not synchronized with solar noon: synchronism with solar noon $( \pm 1 / 2 \mathrm{~h})$ actually occurs every 6 to 7 days, as a result of the interaction between lunar (tide) and solar (night-day) forcing functions.

Similar dynamics are predicted for the depth-integrated gross phytoplankton production (GPPz), as illustrated in Fig. 11b (black line) which represents a chlorophyll-specific value (GPPz divided by the chlorophyll $a$ concentration): using this biomass-specific value removes the day-to-day variation of integrated phytoplankton production due to biomass growth (or decay) . The resulting curve applies to each simulation in the first set, because (a) the water depth is always greater than the euphotic depth and (b) the time variation of $E_{0}$ and $k_{d}$ are identical in all cases. The computed pattern is essentially similar to the one of PAR at $20 \mathrm{~cm}$ (Fig. 11a), although the differences between peak values within a given day are slightly less, a direct consequence of the non-linear relationship between GPP and PAR (Eq. 6). The simulation leads to the rather unexpected result that, in some instances (e.g. day 185), the highest instantaneous depth-integrated GPPz may occur at 9 a.m. and again at 3 p.m. (solar time), (a)

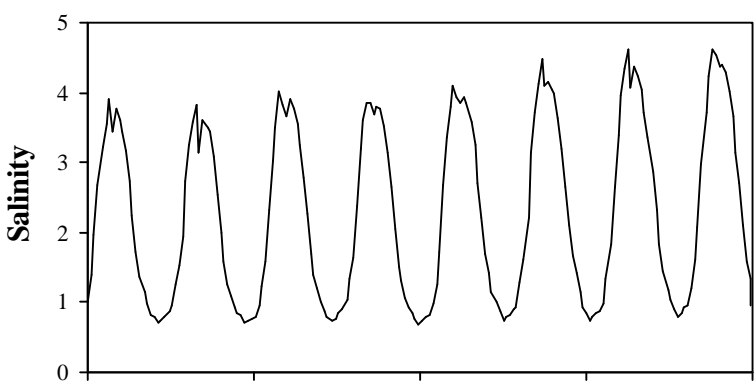

(b)

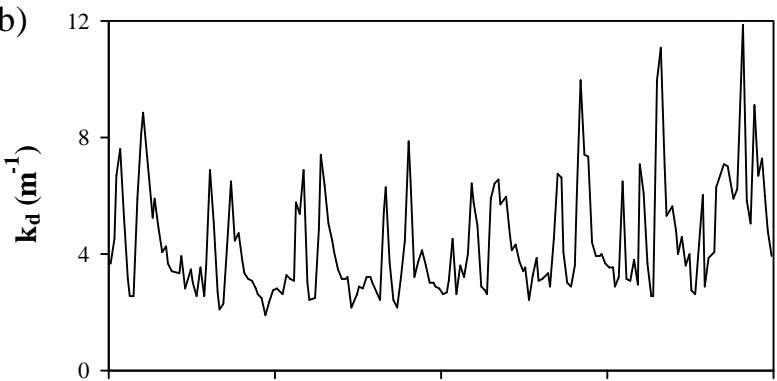

(c)

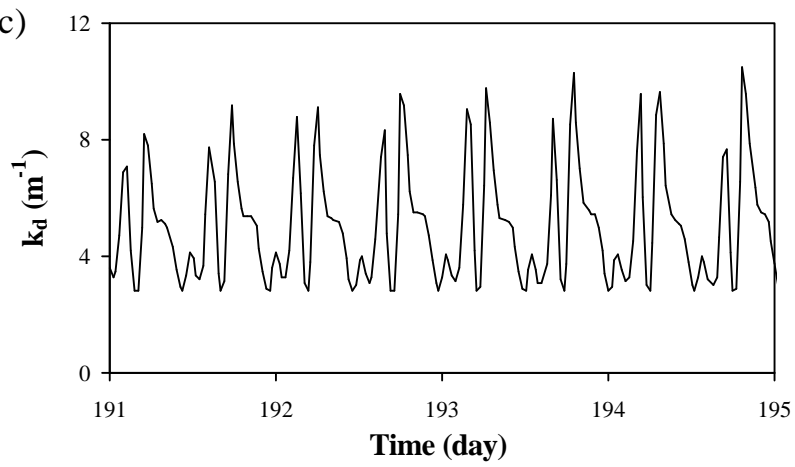

Fig. 10. Variation of (a) salinity and (b) the light attenuation coefficient as measured at a monitoring station in the Scheldt estuary ( $\mathrm{km} \mathrm{80,10}$ to 14 July 1998). (c) Computed variation of the light attenuation coefficient ( $\mathrm{km} \mathrm{80,10}$ to 14 July 1998).

although the incident solar light intensity is far from its maximum at these moments.

A very different time pattern is predicted for $\mathrm{GPPz}$ if an average $k_{d}$ value (i.e. the arithmetic mean over one tide) is used for the simulation (Fig. 11b, grey line). As expected, chlorophyll-specific GPPz closely follows in this case the time evolution of $E_{0}(t)$. More importantly, the depth- and time-integrated GPPzt is very different whether a time dependent or a constant, mean $k_{d}$ value is used. In the latter case, the integrated value is significantly lower, as it can be seen in Fig. 11c, which represents the chlorophyll-specific production, integrated over one day ( $24 \mathrm{~h})$, computed for 5 consecutive days. The daily values obtained when using a variable $k_{d}$ are slightly affected by the shape of the multi-peak pattern of $\mathrm{GPPz}$, ranging from 65 to $67 \mathrm{gC} \cdot \mathrm{m} . \mathrm{gChl}^{-1}$.day ${ }^{-1}$. By contrast, using a constant, average $k_{d}$ leads to a constant, daily 
production equal to $41 \mathrm{gC}$.m.gChl ${ }^{-1}$.day ${ }^{-1}$, an underestimation of 37 to $39 \%$ with respect to the former range of results. These large differences are of course due to the strongly non-linear (bi-exponential) relationship between GPP and $k_{d}$ (Eqs. 6 and 12). Note that using an alternative averaging procedure (i.e. using a geometric instead of an arithmetic mean) does not significantly improve the estimation of the daily GPPzt based on a constant $k_{d}$ value.

One may argue that sedimentation and resuspension mechanisms, that control the SPM dynamics, could affect similarly phytoplankton cells. In some estuaries, short-term variations of chlorophyll $a$ have been observed simultaneously with changes in turbidity (Demers et al., 1987; de Jonge and van den Bergs, 1987; Cloern et al., 1989; Litaker et al., 1993; Lucas, 2003). MacIntyre and Cullen (1996) even conclude that the decrease in mean irradiance caused by resuspension is compensated for by a concomitant increase in suspended chlorophyll $a$, and hence has a negligible influence on GPPz estimates. However, chlorophyll $a$ resuspension is only reported in shallow estuaries $(<2.5 \mathrm{~m})$ or in the shallower areas of deeper estuaries (such as tidal flats $<60 \mathrm{~cm}$ ), where benthic diatoms may often be found. In this paper, we examine systems where the mixing depth is predominantly greater than the euphotic depth, a condition that is not extremely favourable to the development of benthic microalgae (Muylaert et al., 2002). To verify this assumption, simultaneous measurements of turbidity and chlorophyll $a$ have been performed at various depths in the Scheldt estuary (oligo- and mesohaline regions) during a number of tidal cycles. These measurements have never shown any strong, positive correlation between SPM and chlorophyll $a$, suggesting that, in this type of environment, short-term variations in phytoplankton concentration are essentially due to the advection of water masses, rather than to phytoplankton settling and resuspension.

The influence of water depth on the net phytoplankton growth is illustrated in Fig. 12 for the whole set of scenarios. As the average depth increases, the processes responsible for phytoplankton loss (maintenance respiration and mortality) become gradually predominant in the expression of $r$ (Eq. 13). As a result, the phytoplankton biomass rapidly increases in the shallow reservoirs scenarios, while it approaches an exponential decrease (typical of a first-order decay) in the deep reservoirs scenarios (Fig. 12a). Figure 12 also shows the effect of time-averaging the various forcing functions on the long-term trajectories of computed phytoplankton biomass. As expected from previous results, the deviation between the varying $k_{d}$ and the corresponding constant $k_{d}$ cases may become exceedingly large in the long term, because of the cumulative effect of the difference in phytoplankton growth (Figs. 12a and 12b). The trajectories are also increasingly divergent when the average water depth is decreasing. In the case of relatively shallow waters, ignoring the short term variability of $k_{d}$ may even lead to predict a negative biomass growth instead of a positive one. In our
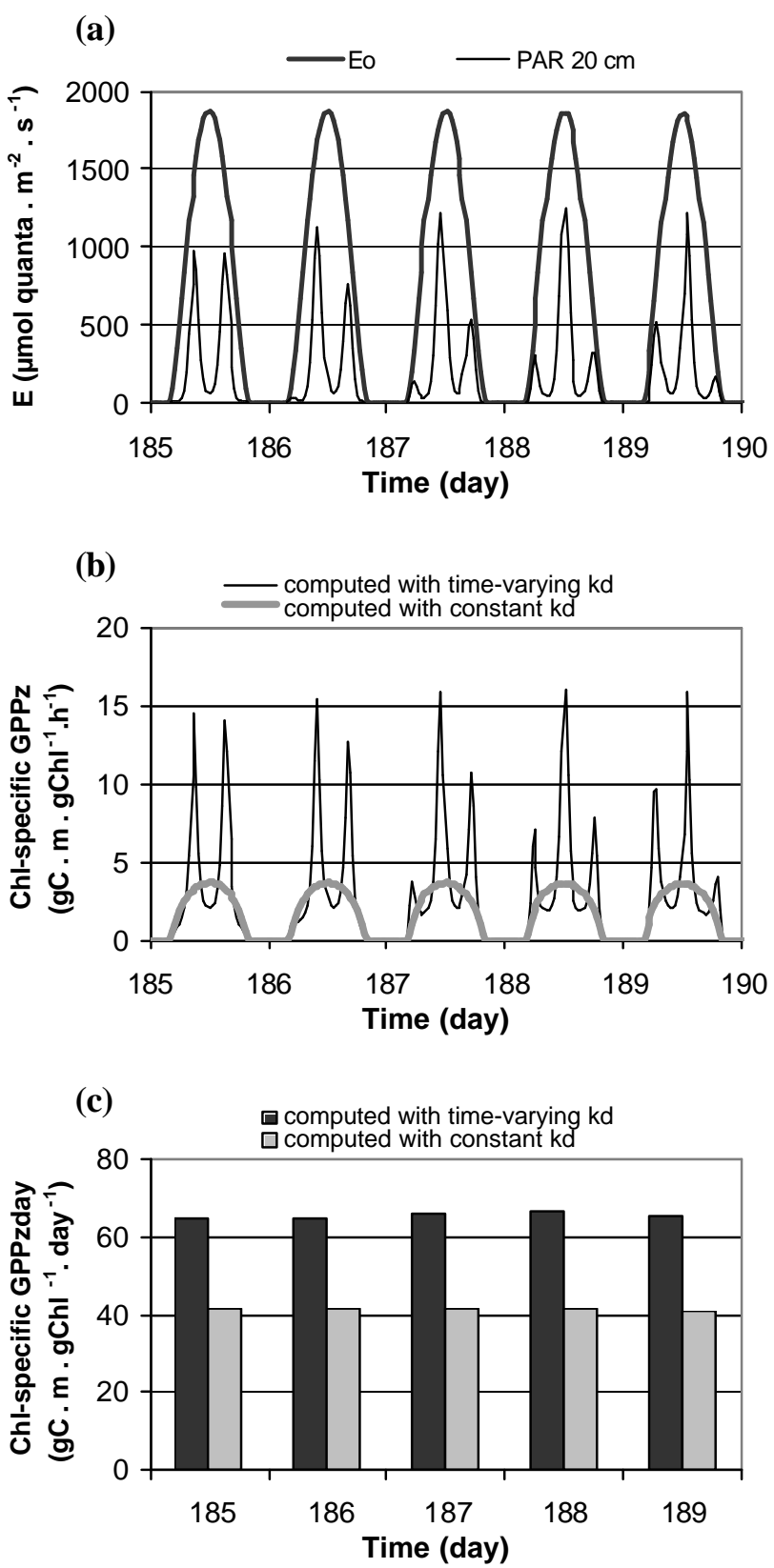

Fig. 11. First set of simulations, days 185 to 190 (4-9 July): (a) Incident solar light (PAR) $E_{0}$ at the surface of the water column and computed PAR at a $20 \mathrm{~cm}$ depth; (b) Depth-integrated, chlorophyll-specific gross primary production. The time variation of the biomass-specific GPPz is computed using a time-varying $k_{d}$ value (black line) or a constant, time-averaged $k_{d}$ value (gray line); (c) Time- and depth-integrated, chlorophyll-specific gross primary production. The daily values of the biomass-specific GPPzt are computed using a time-varying $k_{d}$ value (black bars) or a constant, time-averaged $k_{d}$ value (gray bars).

cases, it can be seen that the average depth under which varying and constant $k_{d}$ models indicate an opposite sign for phytoplankton growth is slightly higher than $6 \mathrm{~m}$. Differences in 

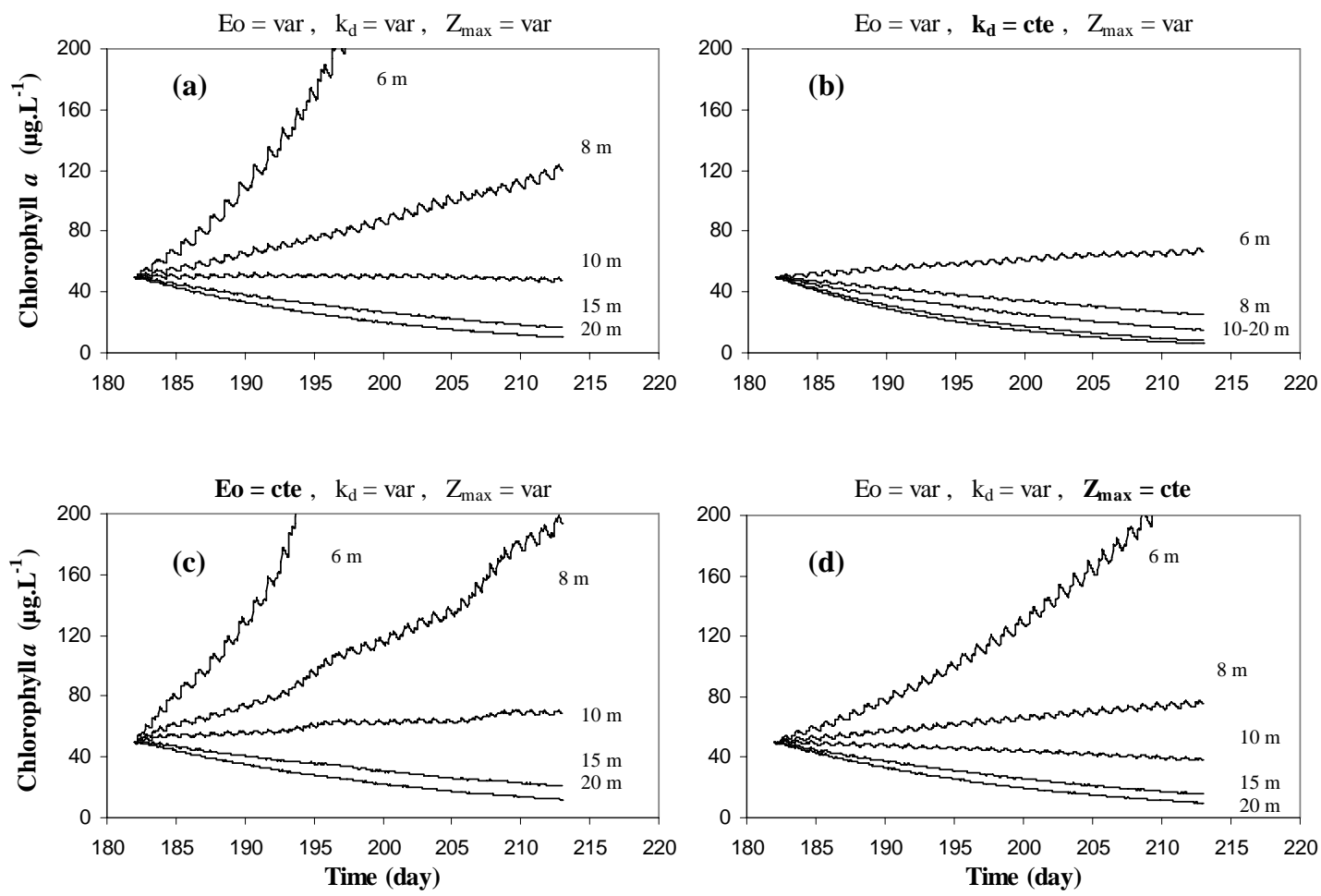

Fig. 12. First set of simulations, days 182 to 212 (1-30 July): Evolution of the net algal biomass (expressed in chlorophyll $a$ ) computed over a 30-days period for a range of bathymetry. The average depth (at mid-tide) is comprised between $6 \mathrm{~m}$ and $20 \mathrm{~m}$, tidal range is equal to $6 \mathrm{~m}$ in all simulations. (a) All forcing functions $\left(E_{0}, k_{d}, z_{\max }\right)$ are varying with time; (b) Using a constant, time-averaged value for the light attenuation coefficient $k_{d}$; (c) Using a constant, time-averaged value for the incident solar irradiance (PAR) $E_{0}$; (d) Using a constant, time-averaged value for the water depth $z_{\max }$.

model responses tend to vanish for an average depth greater than $15 \mathrm{~m}$.

The model response to time-averaging irradiance (Fig. 12c) and water depth (Fig. 12d) has also been investigated. In the case of irradiance, simulations have been made applying a constant, mean $E_{0}$ value for the length of the light period and a null value at night. For constant water depth, mid-tide values have been used. The results show that neglecting the variability of the turbidity is by far the most important source of deviation in the estimation of net phytoplankton growth. Neglecting the tidal variation of the water depth also leads in our case to an underestimation of the net biomass growth, as already pointed out by Lucas and Cloern (2002), but the effect is not as strong as the former one and is only noticeable for average depths less than about $8 \mathrm{~m}$. Finally, using an average irradiance leads to an overestimation, although this effect only takes some importance in the long term and in the shallowest systems.

\subsection{Second set of simulations}

The application of simplified periodic forcing functions to the case of a well-mixed, oscillating-depth reservoir gives a conceptual understanding of the coupling between sediment dynamics, light climate in the water column and phytoplankton production. To advance one step further in the analysis, more complex forcing functions are now considered. They are typical of two locations within the Scheldt estuary, i.e. the brackish, deep area around the harbour of Antwerp $(\mathrm{km}$ $80)$ and the fresh water, shallow zone situated in the tidal estuary, about $40 \mathrm{~km}$ upstream from the former. Note that our purpose here is clearly not to develop a model of the Scheldt estuary, a task that would require to consider the complex lateral and longitudinal bathymetry of the estuary, as well as the role of transport mechanisms and mass exchanges in this complex system. We rather try to follow the same approach as the one used by Lucas et al. (1999a and b) in their study of the processes governing phytoplankton blooms in SSFB. Quoting these authors, we use the Scheldt as a "natural laboratory" and our model for "numerical experiments" in order to "gain insight into physical-biological mechanisms potentially important to a broad class of estuaries".

In the Scheldt estuary, longitudinal profiles of SPM and of $k_{d}$ result in a strong landwards decrease of the water transparency (Fig. 13). However, the complexity of the forcing functions and of their temporal interactions makes the direct interpretation of this pattern rather difficult. Indeed, 


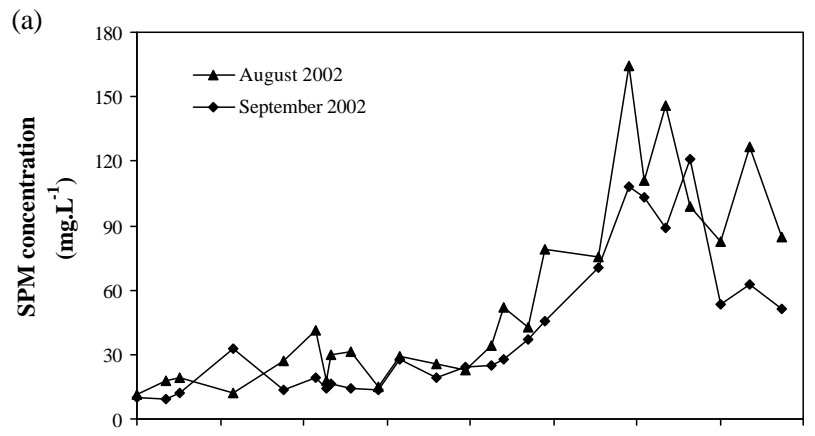

(b)

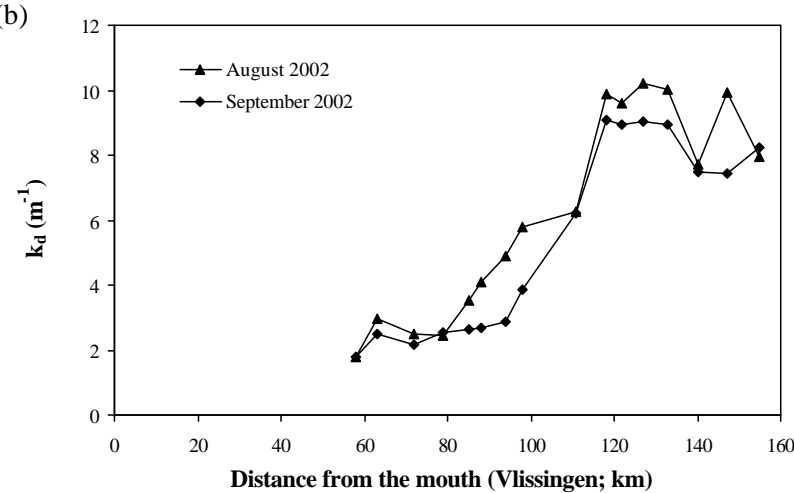

Fig. 13. Longitudinal distribution of (a) suspended solids concentration and (b) light attenuation coefficient along the Scheldt estuary. Location 1 (shallow area) is at $\mathrm{km} 120$ and location 2 (deeper area) is at $\mathrm{km} 80$.

when applying our reservoir model to both selected locations, a positive net phytoplankton growth is predicted at the more turbid one (location 1 , shallow site), whereas a negative net phytoplankton growth is simulated at location 2 (deeper site), in spite of the lower SPM concentration (Fig. 14, kd-v curves). In the absence of longitudinal transport, our model predicts a three-fold increase in algal biomass (expressed as chlorophyll $a$ concentration) over a one-month period at location 1 . In contrast, the chlorophyll $a$ value is reduced by a factor of about $30 \%$ at location 2 within the same period. The main reason for this behaviour originates from the difference of bathymetry at both sites, location 2 displaying an average water depth approximately twice as large as the value at location 1. Although our purpose is not to model the longitudinal phytoplankton gradient in the estuary, we can associate these results with field measurements of chlorophyll $a$ concentrations in the Scheldt estuary. Indeed, an increasing biomass concentration in the seaward direction is only possible if the depth-integrated phytoplankton growth, as estimated with the present zero-dimensional model, is positive. This is a necessary, but not a sufficient condition. However, a negative depth-integrated phytoplankton growth in the model will always result in a decreasing concentration gradient. Model results are thus not in contradiction with the rapid drop in chlorophyll $a$ concentration that is observed between the two locations (Fig. 15).

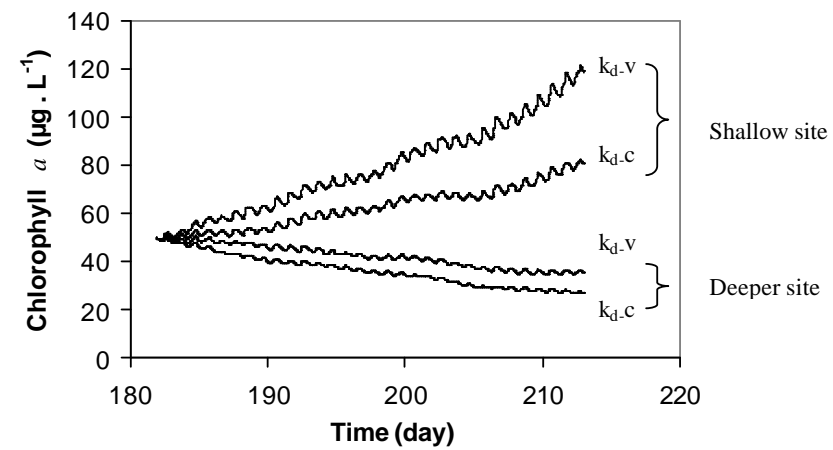

Fig. 14. Second set of simulations, days 182 to 212 (1-30 July): Net chlorophyll $a$ evolution during a 30-day simulation for the shallow area and for the deeper area. Simulations have been performed using time-varying $k_{d}$ ( $k_{d}$-v curves), and time-averaged $k_{d}\left(k_{d}\right.$-c curves).

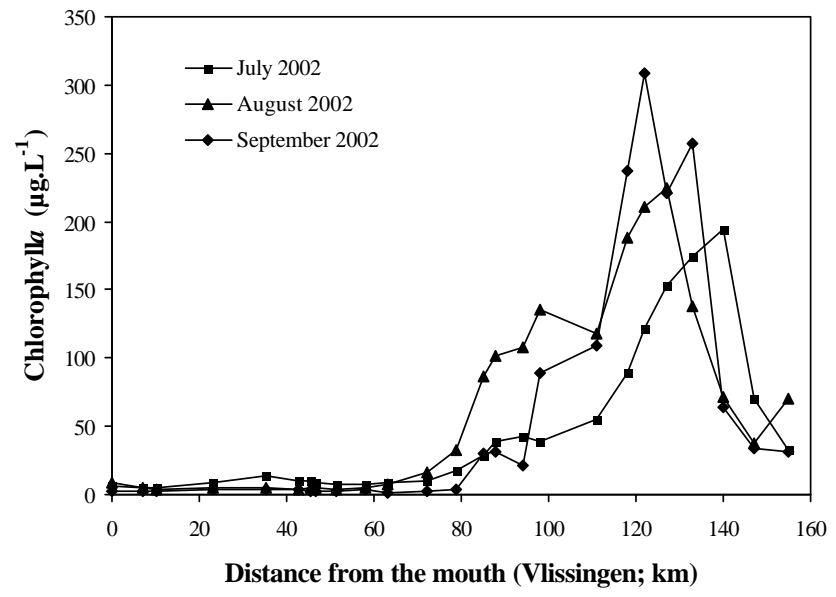

Fig. 15. Longitudinal profile of chlorophyll $a$ concentration along the Scheldt estuary. Location 1 (shallow area) is at $\mathrm{km} 120$ and location 2 (deeper area) is at $\mathrm{km} 80$.

Figure 14 also displays the results of the 30-day simulation when a constant, time-averaged $k_{d}$ is used ( $k_{d}$-c curves). Once again, the net phytoplankton growth exhibits a negative deviation, especially at the shallow site. However, this effect is not strong enough to cause a shift from net biomass growth to net biomass decay, at least in a system where transport processes are not taken into account.

To evaluate the effect of a short-time photoacclimation on GPP and NPP, we have considered a sinusoidal variation of $\alpha^{B}$ and $P_{\max }^{B}$, both having a period of $24 \mathrm{~h}$ and an amplitude equal to $40 \%$ of the constant value in Table 1 . We have tested the case of a peak for photosynthetic parameters in late morning-noon (see Prézelin, 1992), and inversely the case of a minimum in late morning-noon (see Harding et al., 1986). A diel-variation of $\alpha^{B}$ and $P_{\max }^{B}$ significantly affects phytoplankton growth during the month. When photosynthetic parameters exhibit a maximum value at noon, the 
model predicts a four-fold increase in algal biomass over a one-month period at location 1 (shallow site), and a slight decrease in chlorophyll $a$ at location 2 (deeper site). However, if photosynthetic parameters exhibit a minimum value at noon, then chlorophyll $a$ concentration increases by only $50 \%$ at location 1 over a month, and it decreases by $50 \%$ at location 2. Depending on the diel pattern taken into account, photoacclimation may thus enhance or reduce the phytoplankton production. In a more elaborate model of the phytoplankton distribution along the estuary, where transport processes are considered, this may even make the difference between positive and negative population growth at a particular location. Finally, note that the harmonic coupling between $\alpha^{B}, P_{\max }^{B}$ and $k_{d}$ slightly amplifies the importance of using a time-dependent $k_{d}$ instead of a constant mean value. It has already been shown (see 1 st set of simulations) that the daily integrated GPPzt computed with a time-dependent $k_{d}$ was about $37 \%$ higher than the value obtained using an average $k_{d}$. When considering a diel-variation of $\alpha^{B}$ and $P_{\max }^{B}$, this difference between the daily integrated GPPzt's increases from 37 to $40 \%$ when photosynthetic parameters exhibit their minimum value at noon, and to $41 \%$ when they exhibit a peak at noon.

\section{Conclusions}

A number of hypothesis have been invoked to explain the well recognized phytoplankton decay that is often observed along the longitudinal salinity gradient of turbid, macro-tidal estuaries. Among those, factors such as salinity stress, zooplankton grazing and light limitation due to the presence of a turbidity maximum, have been advocated (Soetaert et al., 1994; Kromkamp and Peene, 1995; Vanderborght et al., 2002). In this paper, we have applied a simple model to assess the net phytoplankton growth in a system characterized by high-frequency variations of the physical forcing functions. In this type of system, it is difficult to draw intuitive conclusions about the phytoplankton production-loss balance, because of the complex interactions involved. Simulation results show that, in shallow to moderately deep systems $(<15 \mathrm{~m})$, this balance is strongly affected by the shortterm ( $\sim$ hourly) fluctuations of the light regime, in particular by those linked to the tidal dynamics of SPM. We have also demonstrated that the interplay between tidal and nychtemeral oscillations has to be resolved at least at the hourly timescale. This is a direct consequence of the different frequencies of the physical forcing functions $\left(E_{0}, k_{d}, z_{\max }\right)$, which results in a complex pattern of phytoplankton production at this timescale. Comparison between simulations using temporally resolved and averaged forcing functions indicate that the latter approach leads to significant errors in the estimation of estuarine productivity, especially in turbid and shallow areas $(<8 \mathrm{~m})$.
Acknowledgements. We thank D. Bajura, M. Loijens and N. Roevros for their participation in analytical work and field missions. We also thank K. Muylaert and two anonymous reviewers for their constructive feedback. The support of the "Administratie Waterwegen en Zeewezen" of the Ministry of the Flemish Community and of the MUMM (Management Unit of the Mathematical Model of the North Sea, Royal Belgian Institute of Natural Sciences) is gratefully acknowledged. This research has been supported by the E.U. project EUROTROPH (EVK3-CT-2000-00040). The Belgian FRIA ("Fonds pour la Recherche dans l'Industrie et l'Agriculture") and the "Fondation Baron Van Buuren" have granted the work of one of the authors (X.D.).

Edited by: J. Middelburg

\section{References}

Boyer, J. N., Christian, R. R., and Stanley, D. W.: Patterns of phytoplankton primary productivity in the Neuse River estuary, North Carolina, USA, Mar. Ecol. Prog. Ser., 97, 287-297, 1993.

Cloern, J. E.: Turbidity as a control on phytoplankton biomass and productivity in estuaries, Cont. Shelf Res., 7, 1367-1381, 1987.

Cloern, J. E., Powell, T. M., and Huzzey, L. M.: Spatial and temporal variability in South San Francisco Bay (USA), II. Temporal changes in salinity, suspended sediments, and phytoplankton biomass and productivity over tidal time scales, Estuarine, Coast. Shelf Sci., 28, 599-613, 1989.

Cole, B. E.: Temporal and spatial patterns of phytoplankton production in Tomales Bay, California, USA, Estuarine, Coast. Shelf Sci., 28, 103-115, 1989.

Cole, B. E. and Cloern, J. E.: Significance of biomass and light availability to phytoplankton productivity in San Francisco Bay, Mar. Ecol. Prog. Ser., 17, 15-24, 1984.

Cole, B. E. and Cloern, J. E.: An empirical model for estimating phytoplankton productivity in estuaries, Mar. Ecol. Prog. Ser., 36, 299-305, 1987.

Cole, J. J., Caraco, N. F., and Peierls, B. L.: Can phytoplankton maintain a positive carbon balance in a turbid, freshwater, tidal estuary?, Limnology and Oceanography, 37, 1608-1617, 1992.

Cullen, J. J. and Lewis, M. R.: The kinetics of algal photoadaptation in the context of vertical mixing, J. Plankt. Res., 10, 1039-1063, 1988.

de Jonge, V. N. and van den Bergs, J.: Experiments on the resuspension of estuarine sediments containing benthic diatoms, Estuarine, Coast. Shelf Sci., 24, 725-740, 1987.

Demers, S., Legendre, L., and Therriault, J.-C.: Phytoplankton responses to vertical tidal mixing, in: Tidal mixing and plankton dynamics, edited by: Bowman, J., Yentsch, M., and Peterson W. T., Springer-Verlag, Berlin - Heidelberg, 1986.

Demers, S., Therriault, J.-C., Bourget, E., and Abdourrahmane, B.: Resuspension in the shallow sublittoral zone of a macrotidal estuarine environment: wind influence, Limnology and Oceanography, 32, 327-339, 1987.

Di Toro, D. M.: Optics of turbid estuarine waters: approximation and application, Water Res., 12, 1059-1068, 1978.

Falkowski, P. G. and Raven, J. A.: Aquatic Photosynthesis, Blackwell Science Ltd., 1997.

Fasham, M. J. R.: Variations in the seasonal cycle of biological production in subarctic oceans: a model sensitivity analysis, Deep- 
Sea Research I, 42, 1111-1149, 1995.

Fasham, M. J. R., Ducklow, H., and McKelvie, S. M.: A nitrogenbased model of plankton dynamics in the oceanic mixed layer, $\mathrm{J}$. Mar. Res., 48, 591-639, 1990.

Fettweis, M., Sas, M., and Monbaliu, J.: Seasonal, neap-spring and tidal variation of cohesive sediment concentration in the Scheldt estuary, Belgium, Estuarine, Coast. Shelf Sci., 47, 21-36, 1998.

Fichez, R., Jickells, T. D., and Edmunds, H. M.: Algal blooms in high turbidity, a result of the conflicting consequences of turbulence on nutrient cycling in a shallow water estuary, Estuarine, Coast. Shelf Sci., 35, 577-592, 1992.

Geider, R. J., MacIntyre, H. L., and Kana, T. M.: A dynamic model of photoadaptation in phytoplankton, Limnology and Oceanography, 41, 1-15, 1996.

Geider, R. J., MacIntyre, H. L., and Kana, T. M.: Dynamic model of phytoplankton growth and acclimation: responses of the balanced growth rate and the chlorophyll a:carbon ratio to light, nutrient-limitation and temperature, Mar. Ecol. Prog. Ser., 148, 187-200, 1997.

Geider, R. J., MacIntyre, H. L., and Kana, T. M.: A dynamic regulatory model of phytoplanktonic acclimation to light, nutrients, and temperature, Limnology and Oceanography, 43, 679-694, 1998.

Gilstad, M., Johnsen, G., and Sakshaug, E.: Photosynthetic parameters, pigment composition and respiration rates of the marine diatom Skeletonema Costatum grown in continuous light and a 12:12 h light-dark cycle, J. Plankt. Res., 15, 939-951, 1993.

Grobbelaar, J. U.: Phytoplankton productivity in turbid waters, J. Plankt. Res., 7, 653-663, 1985.

Han, B.-P.: A mechanistic model of algal photoinhibition induced by photodamage to photosystem-II, J. Theor. Biol., 214, 519527, 2002

Hansell, D. A. and Carlson, C. A.: Net community production of dissolved organic carbon, Global Biogeochemical Cycles, 12, 443-453, 1998.

Harding, L. W. J., Meeson, B. W., and Fisher, T. R. J.: Phytoplankton production in two east coast estuaries: photosynthesis-light functions and patterns of carbon assimilation in Chesapeake and Delaware Bays, Estuarine, Coast. Shelf Sci., 23, 773-806, 1986.

Heip, C. H. R., Goosen, N., Herman, P. M. J., Kromkamp, J., Middelburg, J. J., and Soetaert, K.: Production and consumption of biological particles in temperate tidal estuaries, Oceanography and Marine Biology: an Annual Review, 33, 1-149, 1995.

Irigoien, X. and Castel, J.: Light limitation and distribution of chlorophyll pigments in a highly turbid estuary: the Gironde (SW France), Estuarine, Coast. Shelf Sci., 44, 507-517, 1997.

I.R.M.: Bulletin Mensuel des Observations Climatologiques de l'Institut Royal Météorologique de Belgique, Juillet 1999, partie II, edited by: Malcorps, H., 1999.

Kana, T. M., Geider, R. J. and Critchley, C.: Regulation of photosynthetic pigments in micro-algae by multiple environmental factors: a dynamic balance hypothesis, New Phytologist, 137, 629-638, 1997.

Keller, A. A.: Estimating phytoplankton productivity from light availability and biomass in the MERL mesocosms and Narragansett Bay, Mar. Ecol. Prog. Ser., 45, 159-168, 1988.

Kirk, J. T. O.: Light and photosynthesis in aquatic ecosystems, 2nd edn. Cambridge University Press, 1994

Kromkamp, J. and Peene, J.: Possibility of net phytoplankton pri- mary production in the turbid Schelde Estuary (SW Netherlands), Mar. Ecol. Prog. Ser., 121, 249-259, 1995.

Kromkamp, J., Peene, J., van Rijswijk, P., Sandee, A., and Goosen, N.: Nutrients, light and primary production by phytoplankton and microphytobenthos in the eutrophic, turbid Westerschelde estuary (The Netherlands), Hydrobiologia, 311, 9-19, 1995.

Lancelot, C., Hannon, E., Becquevort, S., Veth, C., and de Baar, H. J. W.: Modeling phytoplankton blooms and carbon export production in the Southern Ocean: dominant controls by light and iron in the Atlantic sector in Austral spring 1992, Deep-Sea Research I, 47, 1621-1662, 2000.

Lancelot, C., Mathot, S., and Owens, N. J. P.: Modelling protein synthesis, a step to an accurate estimate of net primary production: Phaeocystis pouchetii colonies in Belgian coastal waters, Mar. Ecol. Prog. Ser., 32, 193-202, 1986.

Lancelot, C., Veth, C., and Mathot, S.: Modelling ice-edge phytopankton bloom in the Scotia-Weddell sea sector of the Southern Ocean during spring 1988, J. Mar. Sci., 2, 333-346, 1991.

Langdon, C.: On the causes of interspecific differences in the growth-irradiance relationship for phytoplankton, II. A general review, J. Plankt. Res., 10, 1291-1312, 1988.

Langdon, C.: The significance of respiration in production measurements based on oxygen, ICES Mar. Sci. Symp., 197, 69-78, 1993.

Lewitus, A. J. and. Kana, T. M.: Light respiration in six estuarine phytoplankton species: contrasts under photoautotrophic and mixotrophic growth conditions, J. Phycol., 31, 754-761, 1995.

Litaker, W., Duke, C. S., Kenney, B. E., and Ramus, J.: Shortterm environmental variability and phytoplankton abundance in a shallow tidal estuary, II. Spring and fall, Mar. Ecol. Prog. Ser., 94, 141-154, 1993.

Lucas, C. H.: Observations of resuspended diatoms in the turbid tidal edge, J. Sea Res., 50, 301-308, 2003.

Lucas, L. V. and Cloern, J. E.: Effects of tidal shallowing and deepening on phytoplankton production dynamics: a modeling study, Estuaries, 25, 497-507, 2002.

Lucas, L. V., Koseff, J. R., Cloern, J. E., Monismith, S. G., and Thompson, J. K.: Processes governing phytoplankton blooms in estuaries, I. The local producion-loss balance, Mar. Ecol. Prog. Ser., 187, 1-15, 1999a.

Lucas, L. V., Koseff, J. R., Monismith, S. G., Cloern, J. E., and Thompson, J. K.: Processes governing phytoplankton blooms in estuaries, II. The role of horizontal transport, Mar. Ecol. Prog. Ser., 187, 17-30, 1999b.

Macedo, M. F., Ferreira, J. G., and Duarte, P.: Dynamic behaviour of photosynthesis-irradiance curves determined from oxygen production during variable incubation periods, Mar. Ecol. Prog. Ser., 165, 31-43, 1998.

MacIntyre, H. L. and Cullen, J. J.: Primary production by suspended and benthic microalgae in a turbid estuary: time-scales of variability in San Antonio Bay, Texas, Mar. Ecol. Prog. Ser., 145, 245-268, 1996.

MacIntyre, H. L., Kana, T. M., Anning, T., and Geider, R. J.: Photoacclimation of photosynthesis irradiance response curves and photosynthetic pigments in microalgae and cyanobacteria (Review), J. Phycol., 38, 17-38, 2002.

Mague, T. H., Friberg, E., Hughes, D. J., and Morris, I.: Extracellular release of carbon by marine phytoplankton: a physiological approach, Limnology and Oceanography, 25, 262-279, 1980. 
Malinsky-Rushansky, N. Z. and Legrand, C.: Excretion of dissolved organic carbon by phytoplankton of different sizes and subsequent bacterial uptake, Mar. Ecol. Prog. Ser., 132, 249-255, 1996.

Mallin, M. A. and Paerl, H. W.: Effects of variable irradiance on phytoplankton productivity in shallow estuaries, Limnology and Oceanography, 37, 54-62, 1992.

May, C. L., Koseff, J. R., Lucas, L. V., Cloern, J. E., and Schoellhamer, D. H.: Effects of spatial and temporal variability of turbidity on phytoplankton blooms, Mar. Ecol. Prog. Ser., 254, 111128, 2003.

Meeus, J.: Astronomical algorithms, Willmann-Bell, Richmond, 2nd ed., 477 p., 1999.

Melis, A.: Photosystem-II damage and repair cycle in chloroplasts: what modulates the rate of photodamage in vivo?, Trends in Plant Science, 4, 130-135, 1999.

Morán, X. A. G. and Estrada, M.: Phytoplanktonic DOC and POC production in the Bransfield and Gerlache Straits as derived from kinetic experiments of ${ }^{14} \mathrm{C}$ incorporation, Deep-Sea Research II, 49, 769-786, 2002.

Muylaert, K., Van Nieuwerburgh, L., Sabbe, K., and Vyverman, W.: Microphytobenthos communities of the brackish to freshwater tidal reaches of the Schelde estuary (Belgium), Belgian Journal of Botany, 135, 15-26, 2002.

Otero, A. and Vincenzini, M.: Nostoc (cyanophyceae) goes nude: extracellular polysaccharides serve as a sink for reducing power under unbalanced C/N metabolism, J. Phycol., 40, 74-81, 2004.

Pahl-Wostl, C. and Imboden, D.M.: DYPHORA - a dynamic model for the rate of photosynthesis of algae, J. Plankt. Res., 12, 12071221, 1990.

Platt, T., Gallegos, C. L., and Harrison, W. G.: Photoinhibition of photosynthesis in natural assemblages of marine phytoplankton, J. Mar. Res., 38, 687-701, 1980.

Postma, H.: Sediment transport and sedimentation, in: Chemistry and Biogeochemistry of Estuaries, edited by: Olausson, E. and Cato, I., John Wiley and Sons Ltd., 153-186, 1980.

Prézelin, B. B.: Diel periodicity in phytoplankton productivity, Hydrobiologia, 238, 1-35, 1992.

Regnier, P., Mouchet, A., Wollast, R., and Ronday, F.: A discussion of methods for estimating residual fluxes in strong tidal estuaries, Cont. Shelf Res., 18, 1543-1571, 1998.
Regnier, P. and Steefel, C. I.: A high resolution estimate of the inorganic nitrogen flux from the Scheldt estuary to the coastal North Sea during a nitrogen-limited algal bloom, spring 1995, Geochimica et Cosmochimica Acta, 63, 1359-1374, 1999.

Reid, P. C., Lancelot, C., Gieskes, W. W. C., Hagmeier, E., and Weichart, G.: Phytoplankton of The North Sea and its dynamics: a review, J. Sea Res., 26, 295-331, 1990.

Soetaert, K., Herman, P. M. J., and Kromkamp, J.: Living in the twilight: estimating net phytoplankton growth in the Westerschelde estuary (The Netherlands) by means of an ecosystem model (MOSES), J. Plankt. Res., 16, 1277-1301, 1994.

Steemann Nielsen, E. and Hansen, V. Kr.: Measurements with the carbon-14 technique of the respiration rates in natural populations of phytoplankton, Deep-Sea Research I, 5, 222-233, 1959.

Sverdrup, H. U.: On conditions for the vernal blooming of phytoplankton, J. Cons. Explor. Mer., 18, 287-295, 1953.

Vanderborght, J. P., Wollast, R., Loijens, M., and Regnier, P.: Application of a transport-reaction model to the estimation of biogas fluxes in the Scheldt estuary, Biogeochemistry, 59, 207-237, 2002.

Verbanck, M.: Sediment-laden flows over fully-developed bedforms: first and second harmonics in a shallow, pseudo-2D turbulence environment, in: Shallow Flows, edited by: Jirka, G. H and Uijttewaal, W. S. J., TU Delft, II 231-II 236, 2003.

Vila, X., Colomer, J., and Garcia-Gil, L. J.: Modelling spectral irradiance in freshwater in relation to phytoplankton and solar radiation, Ecological Modelling, 87, 59-68, 1996.

Weger, H. G., Herzig, R., Falkowski, P. G., and Turpin, D. H.: Respiratory losses in the light in a marine diatom: measurements by short-term mass spectrometry, Limnology and Oceanography, 34, 1153-1161, 1989.

Williams, P. J. 1. and Lefèvre, D.: Algal ${ }^{14} \mathrm{C}$ and total carbon metabolisms, 1. Models to account for the physiological processes of respiration and recycling, J. Plankt. Res., 18, 19411959, 1996.

Wofsy, S. C.: A simple model to predict extinction coefficients and phytoplankton biomass in eutrophic waters, Limnology and Oceanography, 28, 1144-1155, 1983.

Wollast, R.: The Scheldt estuary, in: Pollution of the North Sea: an assessment, edited by: Salomons, W., Bayne, B. L., Duursma, E. K., and Förstner U., Springer-Verlag, 183-193, 1988. 